\title{
VASONEUROSIS WITH EYE-SYMPTOMS
}

B Y

BÉLA BOROS, M.D.

FROM THE DEPARTMENT OF OPHTHALMOLOGIE OF THE ELISABETHUNIVERSITY, PÉCS, HUNGARY

PROFESSOR : DR. CONRAD ALBRICH

THE significance of the innervation troubles of the bloodvesselsparticularly since Richter's experiments showed that they may be limited to certain regions, even to one of the nourishing-branches - deserves greater attention in the diagnosis of eye disease.

In the following we record a case, which is a most instructive instance of a temporary innervation trouble.

A man, aged 32 years, was several times under our observation, suffering with slight conjunctivitis. He said, he was afraid to open his eyes in the morning, for often he felt pains in them, and they became injected. These symptoms passed away in about one and a half hours. As, objectively, we were never able to see anything more than a slight conjunctivitis, he received suitable treatment. Once, he came to the clinic in the morning alarmed, reporting that he was roused from sleep by the ring of the telephone; when getting up the sunshine suddenly got into his eyes, and consequently he felt the above mentioned symptoms, only much stronger. His right eye got very red, he felt a sharp pain in it, so that he didn't dare to open it, and subsequently felt a violent throbbing in his head.

On examining him we found that the right eye-lids were somewhat swollen, photophobia was present, the conjunctiva injected, and strong ciliary injection. On touching the eyeball the patient complained of great pain. As he was very neurasthenic, we met with great difficulty in examining him at all.

The corneal epithelium was intact. No staining with fluorescein could be seen. The reflex of the cornea was present. Deep in the lower part of the cornea a slight haze was present. Descemet's wrinkles were not noticeable, only a few unusually thick nerves. A regular contour of the endothelium could not be observed. The iris was slightly hyperaemic, no precipitates were present.

Pain in the ciliary region suggested early iritis. The size of the bloodvessels of the eyeground was normal. The tension was $15 \mathrm{~mm} . \mathrm{Hg}$ in the right eye, and $21 \mathrm{~mm} . \mathrm{Hg}$ in the left, which was intact. During the attack the blood pressure was $120 / 80 \mathrm{Hg}$. A scotoma was not found. Visual acuity was $6 / 9$, and normal in the left eye. Marked fulness and throbbing of the blood 
vessels on the right temple was apparent. We kept the invalid in a dark room and observed him every 5-10 minutes. The symptoms vanished before our very eyes. The ciliary injection nearly entirely passed away and the sensitiveness ceased. The throbbing and fulness of the bloodvessels of the temple, which were noticeable some minutes before, ceased, but he felt numbed. Next day the invalid was well, his eyes were normal, his visual acuity became perfect. The tension of the right eye became as normal as the left one $(20-21 \mathrm{Hg})$. The substance of the cornea, as could be seen with the slit-lamp, was clear, the formerly swollen nerves were scarcely visible.

Questioned, the patient stated that these symptoms occurred often but in much slighter degree. His mother and grandfather suffered from migraine. He was a victim of migraine too.

During these above mentioned attacks his head did not ache, he only felt a kind of congestion. He was neurasthenic and showed a vivid dermographismus. Complement fixation was negative.

We knew several members of his family, some of whom were neuropathic, and showed degenerative stigmata.

To explain the symptoms described here, we were facing a case of a transient half-sided bloodvessel crisis, which was caused, as it seems, by certain constitutional changes, connected with reflex causes, which apparently occurred repeatedly. Among the symptoms, that of the transient thickening of the nerves in the cornea deserves our attention, as well as the intermittent œedema of the cornea. The common characteristics of these cases are (13 such cases are mentioned in the literature), that they appear suddenly in the morning, pass away quickly, are connected with codema of the cornea, with changes of the epithelium and endothelium, and with enlargement of the nerves of the cornea.

But the intermittent odema of the cornea is never accompanied by signs of irritation or by diminution of the tension. (Aubineau, François, Hambresin.) The above-mentioned case is only like the transient œdema of the cornea, it occurs in the morning, and is characterized by a temporary phase. However, these cases differ on the grounds that diminution of the tension, and strong injection, are signs of an acute circulatory trouble. These symptoms remind us rather of the intermittent form of ophthalmomalacia. Reis, according to his observations, states that ophthalmomalacia can appear in various forms. According to him the entire groups of corneal changes which are of the same nature, and are mentioned in the literature under various names, such as "Buchstabenkeratitis" described by Haab, the "Gitterförmige Hornhauttrübung" by Caspar, the neuritis cornealis and so on, as well as ophthalmomalacia, are due to neurotic causes. 
Undoubtedly the essence of the case described here, was vaso-neurosis, involving lessening of the bloodvessel-tone. Whether we consider this syndrome as ophthalmomalacia, or intermittent corneal œdema, it is essential to mention the researches, which reveal the above mentioned clinical symptoms. In these researches the authors naturally were examining the part played by the endothelium of the cornea. Fuchs stated that in the human eye, the aqueous could not enter the cornea after destruction of the endothelium; but against this, are the researches of Hippel, Bullot, Lohr and Graf and the statements of Fischer, which show that a diminution of concentration of the aqueous humour amounting to 0.05 per cent. causes œedema of the cornea. The authors think that the primary change is imbibition of fluid by the cornea as a result of changes in the innervation of the bloodvessels. The concentration of the aqueous is thus reduced, with resultant changes in the endothelium.

In consequence of the endothelial-barrier trouble, the substance of the cornea becomes imbibed, the "Leitplasmodium" (Nageotte, Reiser) which envelops the nerves will also be œdematous. That is why the corneal nerves swell during the blood vessel crisis and they are well visible aided by a slit-lamp. However, this disappears when the fit passes.

Though the symptoms of our case remind us of intermittent corneal oedema, yet we think it more suitable to consider it as a variety of ophthalmomalacia, because an obvious formation of Descemet's wrinkles could not be seen during the observation of the patient. Perhaps, we might take the mixed symptoms of both diseases of the cornea as an intermittent form of corneal œdema, differing only in quantitative degree from the well-known troubles of ophthalmomalacia, described by older authors.

It would be rather difficult to dispute the independent thoroughness of the two diagnoses. Their mutual feature is, that both are originated by neurological causes. That notion in connection with the case of our patient we can verify.

Taking the blood vessel troubles into consideration, which occur in the family of the patient, the case is due to an inherited constitution, as the cause of the vegetative stigmatisation.

\section{LITERATURE}

Graf.-Chronisches intermittierendes Hornhautoedem als Ausdruck einer Angioneurose. Zeitschr.f. Augenheilk., Bd. XCI.

NAEGEL1.-Allgemeine Konstitutionslehre.

OPPENHEIM. - Lehrbuch der Nervenkrankheiten.

REIS.-Ueber Ophthalmomalacie. Arch. f. Ophthal., Bd. CV 